\title{
Receptionists' experiences of occupational violence in general practice: a qualitative study
}

\author{
Parker Magin, Terry Joyce, Jon Adams, Susan Goode and Georgina Cotter
}

\begin{abstract}
Background

The significance of occupational violence in general practice is well established, but research has focused almost exclusively on the experiences of GPs.

Only limited research has examined the role of general practice receptionists despite their acknowledged vulnerability to violent patient behaviour. No qualitative research has explored this problem.
\end{abstract}

Aim

To explore the experiences of general practice receptionists regarding occupational violence and the effects of violence on their psychological and emotional wellbeing and on their work satisfaction and performance.

Design of study

Qualitative study.

\section{Setting}

Constituent practices of an Australian network of research general practices. Practices were located in a range of socioeconomic settings.

\section{Method}

Semi-structured interviews were conducted with practice receptionists. The interviews were audiotaped, transcribed, and subjected to thematic analysis employing a process of constant comparison in which data collection and analysis were cumulative and concurrent. Qualitative written responses from a crosssectional questionnaire-based study performed concurrently with the qualitative study were similarly analysed.

\section{Results}

Nineteen interviews were conducted and 12 written responses were received. Violence was found to be a common, sometimes pervasive, experience of many receptionists. Verbal abuse, both 'across the counter' and telephone abuse, was the most prominent form of violence, although other violence, including assault and threats with guns, was reported. Experiences of violence could have marked emotional and psychological effects and could adversely affect job satisfaction, performance, and commitment.

\section{Conclusion}

It is apparent that occupational violence is a whole-ofpractice problem and strategies for GP and staff safety will need to take a whole-of-practice approach.

Keywords

family practice; medical receptionists; violence.

\section{INTRODUCTION}

Occupational violence in the wider setting has been characterised as 'external' (related to having 'cash at hand', that is, related to robbery), 'client initiated', or 'internal' (bullying). ${ }^{1}$ It is the second of these to which workers in general practice are particularly vulnerable. Occupational violence can have long-term consequences for the wellbeing of victims, including serious psychiatric sequelae. ${ }^{2}$ The healthcare workforce is at risk of violence in their everyday working lives, ${ }^{3,4}$ and, in the UK, violence is more prevalent towards GPs than specialist doctors. ${ }^{5} \mathrm{~A}$ cross-sectional study performed in urban areas of the same Australian state as the study reported here found that $64 \%$ of GPs had experienced violence at work over a 12-month period. ${ }^{6}$ Thus, it is not surprising that violence directed towards GPs and their staff has been recognised as a significant occupational health issue., ${ }^{7,8}$

Previous research has suggested that violence against receptionists is more common in general practice than in hospital settings, ${ }^{5}$ and that receptionists may be exposed mainly to 'low-level

P Magin, PhD, FRACGP, senior lecturer, director; S Goode, $B S c$, program coordinator, Primary Health Care Research Evaluation and Development program; G Cotter, BA, Grad Cert Applied Science (Social Stats), project officer, Discipline of General Practice, University of Newcastle, Newcastle, NSW; T Joyce, RN, PhD, research academic; J Adams, MA, PhD, head, Discipline of Social Science, School of Population Health, University of Queensland, Herston, QLD, Australia.

Address for correspondence

Parker Magin, University of Newcastle, General Practice, Discipline of General Practice, Newbolds Building, University of Newcastle, University Drive, Callaghan, 2308, Australia. E-mail: parker.magin@newcastle.edu.au

Submitted: 19 November 2008; Editor's response: 16 April 2009; final acceptance: 6 May 2009.

@British Journal of General Practice.

This article was originally online first on 15 July 2009. Cite this article as: Br J Gen Pract 2009; 59: 578-583. Advance online publication. DOI: 10.3399/bjgp09X453783 
violence' - especially verbal abuse - when compared to GPs. ${ }^{9,10}$ But these latter findings are based on reports of GPs, not on those of the receptionists themselves.

Three studies have specifically examined occupational violence involving general practice receptionists with receptionists as the participants. These are quantitative studies conducted in the Republic of Ireland ${ }^{11}$ and the UK, ${ }^{12,13}$ and have demonstrated prevalence of violence comparable to that of GPs: a career prevalence of violence of $62 \%$ for receptionists in the Republic of Ireland, ${ }^{11}$ and a $68 \%$ 12-month prevalence in receptionists in England. ${ }^{12}$ By far the most prevalent form of violence in these studies was verbal abuse ${ }^{11,12}$ (as it has been in studies of GP violence from the UK, ${ }^{5,14-16}$ and Australia ${ }^{6,17}$ ).

Despite being predominantly verbal abuse or other 'Iow level' violence, ${ }^{6}$ previous studies, ${ }^{6,9,10}$ have suggested occupational violence has a considerable effect on GPs' practice and on their mental health. The experience of GP staff regarding this significant issue is less clear. In other occupational settings, 'face-toface' contact with the public has been associated with greater perceived violence risk. ${ }^{3}$ Thus receptionists, in particular, might be thought to be singularly vulnerable given their position in the 'frontline' of practice structure, in their role as 'gatekeeper' to GP services, and in their being (compared to GPs) relatively powerless to adapt their workplace or work practices.

The study reported here is the first qualitative study of occupational violence in general practice receptionists. It aimed to explore receptionists' experiences of occupational violence and the effects of violence on their psychological and emotional wellbeing and on their work satisfaction and performance. Such aims lend themselves to qualitative methodology, as previous qualitative research has demonstrated the extent and complexity of the effects of occupational violence on GPs and their practice of medicine. ${ }^{9}$

In this project, violence at work is defined in line with the European Commission as '... incidents where persons are abused, threatened, or assaulted in circumstances related to their work, involving an explicit or implicit challenge to their safety, wellbeing, or health'. ${ }^{8}$

\section{METHOD}

In this study, reception and practice-management staff represented an homogenous 'receptionist' group. Although roles within the practice differed, participants' experiences of violence were comparable. Managers had progressed 'through the ranks', having started their careers as receptionists (and often still performed some general receptionist duties). Also, they were often summoned by junior reception staff in the event

\section{How this fits in}

General practice receptionists are thought to be particularly at risk of

experiencing occupational violence. This is the first qualitative exploration of their

experiences of violence. It finds receptionists to be subjected to considerable

occupational violence, especially verbal abuse, and that this has emotional and

psychological sequelae, and effects their work performance and satisfaction.

of violence or potential violence.

The setting of the study was an Australian network of research general practices (NRGP). Information packages were distributed to receptionist and practice-management staff of the 14 constituent practices of the NRGP inviting participation in the study. Individuals consenting to participation via replypaid envelopes were later interviewed at a time and place of their convenience. The majority of interviews took place at the participant's workplace.

Interviews were conducted by one of two interviewers (a GP and a nurse) from July 2007 to April 2008 and followed a theme-list developed from both previous literature and the study aims. However, reflecting the modified grounded theory methodology of the study, discussions were participant-led and, as data-collection progressed, additional themes for exploration were added as new areas of interest emerged. ${ }^{19}$ Emerging areas and themes for exploration in further interviews were discussed by the two interviewers following individual interviews. Recruitment continued until thematic saturation had been achieved.

Interviews were audiotaped and transcribed. Thematic data analysis was cumulative and concurrent throughout the data collection period with coding and analysis following inductive methods. A code-book was developed as part of the constant comparison coding technique. The code-book labels were applied to individual manuscripts and coded quotations were collated.

Constant comparison involved comparing the emerging codes between each transcript. ${ }^{20}$ The next level of analysis was axial coding and involved a grouping of the first order codes into coherent themes. The final level of analysis involved the examination of relationships and interactions between themes.

Each transcript was coded by the principal researcher, and a third of the transcripts were subjected to comparative coding with a further research team member. Differences in researchers' perspectives were resolved by mutual agreement. Reflexivity was inherent in this process via awareness and consideration of the influence of the researchers' respective professional and academic backgrounds (a GP and a nurse). 
In conjunction with the qualitative interview study, a questionnaire-based cross-sectional study of staff in the NRGP practices was also carried out. In this questionnaire, as well as completing a number of items regarding workplace violence in general practice, responders were given the opportunity of making unstructured comments. These responses were analysed as per the interview transcripts and results were triangulated with those of the interview data.

\section{RESULTS}

Nineteen interviews with receptionists or practice managers from eight separate practices were conducted until thematic saturation had been achieved. All responders were female, reflecting the demographics of these workforces. Responders provided a broad range of personal characteristics (age and years of work in general practice) and practice characteristics (urban and rural, small and large, 'traditional' and 'multidisciplinary', low- and high-socioeconomic status). Researchers also received 12 unstructured written responses on the cross-sectional questionnaire. This represented written responses from $26 \%$ of the receptionists who completed the questionnaire (overall response rates for completion and return of the questionnaire among staff at the practices was $55 \%$ ).

Results are presented as 'overall occurrence of violence', 'types of violence', 'psychological and emotional effects of violence', and 'effects on job satisfaction and performance'.

\section{Overall occurrence of violence}

Perceived frequency of violence varied markedly between practices; however, responders from within the same practice shared consistent perceptions of the level of violence experienced within their practice. Differences in perceived frequency of violence essentially reflected the demographics of the practice patient population: age, life-stage and, especially, socioeconomic status or level of deprivation or unemployment which was also related to levels of drug and alcohol abuse and psychiatric morbidity. A range of violence levels was identified, from perceived 'high frequency' practices to perceived 'low frequency' practices. But the overall picture was one of violence (mainly verbal abuse) being a common aspect of the working lives of many practice staff:

'We get abused probably nearly every day, verbally, by different people and I think you can only take so much before you're actually going to explode.' (Interview 11)

There was a widespread perception that violence was becoming more common. This was quite consistent and appeared to be only weakly related to the level of perceived violence within the particular responder's practice:

'I feel violence within general practice is increasing for non-medical staff members [...] unfortunately I think angry or upset patients are inevitable in general practice.' (Questionnaire 10)

The underlying causes of this increase in violence were thought to be principally increased illicit drug use and an increasing prevalence of mental health illness being managed in general practice:

'That's [violence] always a problem with more and more drugs around.' (Interview 19)

'There's a lot more mental health people ... I think there's a lot more now than what there was then.' (Interview 10)

\section{Types of violence}

While verbal abuse was unquestionably and by far the most common type of violence encountered, other types of violence including 'higher level' violence - assault, threats, property damage, intimidation, manipulation and stalking - were also reported.

Assault was an uncommon occurrence in the working lives of these general practice staff, but nevertheless several responders relayed their experiences of having being assaulted:

'I've had people throw a bag of syringes at me because we don't accept syringes. I said "I'm sorry we can't do that because we don't know where they have been" and she threw them at me ... I've [also] been hit on the head with a walking stick by an elderly patient.' (Interview 1)

Threats were infrequently experienced. Some responders had been threatened with a gun in a waiting room, held up and robbed at gunpoint (after being followed from the surgery with the practice's banking), and threatened with a razor blade. But less dramatic instances were also distressing and unsettling, often because of a difficulty in assessing the 'genuineness' and thus the actual level of risk entailed in the threat:

'It's just that you are threatened. You are really threatened and, this particular scenario I was threatened - and - the whole, the big thing about it was I didn't know what I was dealing with. You've got a patient who is ... very unpredictable.' (Interview 15) 
Another more tangential form of threat was that of threatening the receptionist with responsibility for adverse clinical outcomes. Such incidents took the form of threats related to denial or delay in access to care. A prominent example was the threat of suicide:

\begin{abstract}
'It was a mother who came in and was screaming and swearing at me because she couldn't get an appointment for her daughter. We were doing all we could but it was something that was out of our control ... she was calm and then all of a sudden just clicked and just started swearing at me and walked out saying that if her daughter killed herself, "it would be on your head".' (Interview 4)
\end{abstract}

Intimidation and manipulation were also common. Both were often described as relating to drug-seeking behaviours or to attempts to obtain an appointment. A further observation was that if intimidation or manipulation was unsuccessful - if it didn't produce the desired outcome for the patient (for example, did not result in a prescription for drugs of addiction) the ensuing scenario was often escalation to a further form of violence:

'The outcome is that they need the medication and as long as it is going along and they're thinking that they're eventually going to get there if they can just talk you down it will be OK. But as soon as it starts to turn, that's when you start to get aggression and then that sometimes leads to the violence.' (Interview 17)

But the overwhelming majority of violence suffered by the responders was verbal abuse. Verbal abuse was reported in two settings: 'across the counter' and via telephone. Both were very common, but there were qualitative differences between the two forms of verbal abuse.

'Across the counter' verbal abuse was in many ways more distressing and worrying for the staff due to the inherent potential for escalation into higher level violence. Examples of across the counter verbal abuse included:

'She just screamed out, started swearing, "I'm not $f \ldots$ ___ paying for this $f \ldots$ ___ consult and you know you could all ... " Just sort of swearing and just generally being abusive and slamming doors.' (Interview 14)

Phone abuse was a very particular form of violence - and almost always directed at receptionists rather than other practice staff as they were in the 'front line' of phone contact with patients as well as being in the frontline physically at the practice reception counter:
'There'd always be the verbal violence over the phone, and I think that's just part of the job. It's probably not accepted but it does come with the job as receptionist. You get a lot of aggressive people over the phone.' (Interview 6)

The essential difference between phone and across the counter verbal abuse was the 'licence' that the lack of face-to-face contact gave abusing patients. It was seen as being almost 'anonymous' and lacked the moderating influence of other patients in the waiting room. It could also leave the receptionist feeling powerless and frustrated in that the abusive patient controlled the interaction through their ability to choose to hang up:

'You probably get it more on the phone than what you do face to face. Cause I think people can just say what they want and hang up ... and you're just left sitting there, you can't really say anything or do anything.' (Interview 11)

\section{Psychological and emotional effects of \\ violence}

Sometimes identifiable psychiatric symptomatology was apparent in the sequelae of responders' experiences of violence. But commonly, participants reported non-specific emotional upset in the wake of experiences with violent or aggressive patients, especially after personally-directed abuse, as opposed to more random 'bad behaviour' on the part of perpetrators:

'But it did take me a while to become accustomed to, when I first started here l'd run out the back and cry or run away ... personalising that made me feel like, I suppose, a victim.' (Interview 1)

Personalising the abuse directed at them resulted, for some responders, in self-blame, guilt or decrements in self-worth:

'Well I still do to this day if someone gets a bit aggressive, I just kind of freeze a bit and go "uh uh" like I don't know exactly how to tackle it then and there. It makes you feel about two foot tall kind of thing, you think "oh, God".' (Interview 4)

For some responders, anxiety symptoms related to experiences of violence were identifiable and could be quite severe:

'l just get very panicky inside ... it does put a lot of worry, fear inside of you and then consequently I start to feel hot, heartbeat is going rapidly ... inwardly [my] heart goes fast, I start to get hot. I 


\section{Box 1. Examples of receptionists' questionnaire responses.}

\section{- Overall occurrence of violence}

'I find that patients are more aggressive towards admin/reception staff than they are to the GPs and nurses. They are the first point of contact and take a lot of abuse and are still expected to remain happy and smiling people.' (Questionnaire 30)

'After abusing staff other than the GP, a patient will go into the consult and be their normal self in front of the GP. Often the doctors don't know about patients' abusive side.' (Questionnaire 34)

\section{Types of violence}

'A woman was removed from the practice because of abuse to the GP. She then returned and threw the garbage bin at the reception staff.' (Questionnaire 43)

\section{- Effect on wellbeing and work enjoyment and performance}

'I find it very intimidating. I feel that patients have a lack of understanding of how busy a practice is and how they are run.' (Questionnaire 47)

'Personal verbal abuse hurts more than swearing and should not be tolerated.' (Questionnaire 39)

can feel the sensation of feeling quite tight, inward tightness.' (Interview 2)

Anticipatory symptoms, often represented by responders as fear or apprehension, could also be severe and, in some cases, incapacitating:

'Oh it's horrible. It's really nerve racking ... It's scarier, cause you think "I don't know if they [violent patients] are coming back or are they waiting outside?".' (Interview 17)

For some responders and for some episodes of violence the emotional upset didn't stop at the surgery door: the emotional upset and psychological distress followed them home:

'It has kind of followed me home and I will think about it ... l'll just be thinking about it and I will [be] kind of upset. You just kind of replay it in your head and go "oh that was awful".' (Interview 4)

\section{Effect on work enjoyment and work performance}

The effects of experiences of violence and apprehension regarding risk of violence on responders' enjoyment of their work, their engagement with their job, and their work performance were apparent in the responses of a number of participants:

'And it makes the day longer, harder, you just don't go home feeling "that was good".' (Interview 9)

'Other times, if it happens day after day, you get to the stage where you think "you know, is this really what I want to do in life?". I don't need the stresses of worrying, "are we going to have an incident today?". Yes that can be a situation that I carry with me which isn't very good.' (Interview 2)

Especially with repeated episodes of verbal abuse, responders' commitment to their job and their work could suffer. Several responders reported frustration, fear, or exasperation with violence, aggression, or abuse as leading them to reconsider their employment in general practice; for example:

'I would want to get out my resume and start sending out applications for jobs somewhere else.' (Interview 1)

\section{Questionnaire qualitative responses}

Triangulation of receptionists' qualitative responses on the questionnaire phase of the study with those of the interviewees revealed congruent experiences and attitudes. Examples of the questionnaire responses are presented in Box 1.

\section{DISCUSSION}

\section{Summary of main findings}

Not surprisingly, reported violence in this study was essentially "client initiated" - although there was an example (the robbery on the way to the bank) of 'external' cash-related ${ }^{1}$ violence.

There was marked variability in perceived frequency of violence between different practices, but in all practices verbal abuse (both across the counter and phone abuse) was the predominant type of violence. The between-practice variability in frequency was attributed by responders to differences in practice demographics: socioeconomic status, drug use, and mental illness.

Violence and perceptions of risk had marked effects on the emotional and psychological wellbeing of a number of the responders. The degree or severity of these effects varied and in general was 
not sustained - although some responders reported taking their fears and concerns home with them and many reported adverse effects of experiences of violence on work performance and job satisfaction.

\section{Strengths and limitations of the study}

The qualitative methodology of this study provides a means of complementing and expanding the understanding provided by previous quantitative studies.

The sampling frame of NRGP practices provided a range of urban and rural, large and small, 'traditional' and 'multidisciplinary team' practices, and perceived 'high' and 'low' frequency practices.

\section{Comparison with existing literature}

The findings of variability of frequency of violence between practices, but pervasive violence in some practices, and the predominance of verbal abuse can be considered in the context of an occupational lifetime prevalence of violence of $62 \%$ in receptionists in the Republic of Ireland, ${ }^{11}$ and a 68\% 12-month prevalence in receptionists in England. ${ }^{12}$ The preponderance of verbal violence and the low perceived frequency of physical violence are in keeping with previous studies, both in GPs, ${ }^{6,10,15,17,21,22}$ and receptionists. ${ }^{11,12}$

Responders' attributions of violence to poverty, unemployment, drug use, and high prevalence of mental illness were consistent with previous empirical studies that have identified socioeconomic status, ${ }^{6,12}$ illicit drug use, ${ }^{6}$ and mental illness, ${ }^{6}$ as associations of patient violence.

Psychiatric morbidity, including post-traumatic stress disorder, has been suggested as a possible outcome of assaults against healthcare workers, ${ }^{2,23}$ and workers in other sectors, ${ }^{2}$ but have not been previously explored in the general practice setting.

\section{Implications for future research or clinical practice}

Occupational violence is a pervasive problem in many practices and the emotional sequelae described were considerable and had significant effects on work performance and commitment. There is an occupational health and safety responsibility of GP employers to be aware of, and to address, this important practice issue. This will include staff training in preventing and dealing with violence.

It is also apparent that occupational violence is a whole-of-practice problem and strategies for GP and staff safety will need to take a whole-of-practice approach. Thus, complex interventions incorporating such an approach need to be designed and trialled. Outcome measures must include reception staff as well as GPs' and patients' perspectives.

\section{Funding body}

The study did not receive external funding

\section{Ethics committee}

Ethical approval for this study was obtained from the University of Newcastle Human Research Ethics Committee (Approval number H-368-0207)

\section{Competing interests}

The authors have stated that there are none.

\section{Discuss this article}

Contribute and read comments about this article on the Discussion Forum: http://www.rcgp.org.uk/bjgp-discuss

\section{REFERENCES}

1. Mayhew C. Occupational violence in industrialized countries: types, incidence patterns and 'at risk' groups of workers. In: Gill M, Fisher B, Bowie B, eds. Violence at work: causes patterns and prevention. Portland: Willan Publishing, 2002

2. Hogh A, Viitasara E. A systematic review of longitudinal studies of nonfatal workplace violence. Eur J Work Organ Psychol 2005; 14(3): 291-313.

3. Upson A. Violence at work: findings from the 2002/2003 British Crime Survey. London: Home Office Report, 2004.

4. Health and Policy Economic Research Unit BMA. Violence at work: the experience of UK doctors. London: British Medical Association, 2003.

5. Health and Policy Economic Research Unit BMA. Violence at work: the experience of doctors in Great Britain. London: British Medical Association, 2008.

6. Magin PJ, Adams J, Sibbritt DW, et al. Experiences of occupational violence in Australian urban general practice: a cross-sectional study of GPs. Med J Aust 2005; 183(7): 352-366.

7. Wright NM, Dixon CA, Tompkins CN. Managing violence in primary care: an evidence-based approach. Br J Gen Pract 2003; 53(492): 557-562.

8. Rowe L, Kidd M. Increasing violence in Australian general practice is a public health issue. Med J Aus 2007; 187(2): 118-119.

9. Magin $\mathrm{P}$, Adams J, Ireland $\mathrm{M}$, et al. The response of general practitioners to the threat of violence in their practices: results from a qualitative study. Fam Pract 2006; 23(3): 273-278.

10. Elston MA, Gabe J, Denney D, et al. Violence against doctors: a medical(ised) problem? The case of National Health Service general practitioners. Sociol Health Illn 2002; 24(5): 575-598.

11. Chambers F, Kelly M. Violence at work: the experience of general practice receptionists. Ir Med J 2006; 99(6): 169-171.

12. Dixon CA, Tompkins CN, Allgar VL, Wright NM. Abusive behaviour experienced by primary care receptionists: a cross-sectional survey. Fam Pract 2004; 21(2): 137-139.

13. Bayman $P$, Hussain T. Receptionists' perceptions of violence in general practice. Occup Med (Lond). 2007; 57(7): 492-498.

14. D'Urso P, Hobbs R. Aggression and the general practitioner. BMJ 1989; 298(6666): 97-98.

15. Ness GJ, House A, Ness AR. Aggression and violent behaviour in general practice: population based survey in the north of England. BMJ 2000; 320(7247): 1447-1448.

16. Neville RG. Violent patients in general practice. Practitioner 1986; 230(1422): 1105-1108.

17. Tolhurst H, Baker L, Murray G, et al. Rural general practitioner experience of work-related violence in Australia. Aust J Rural Health 2003; 11(5): 231-236.

18. Wynne R, Clarkin N, Cox T, Griffiths A. Guidance on the prevention of violence at work. Luxembourg: European Commission, DG-V, 1997.

19. Miles M, Huberman A. Early steps in data analysis. Qualitative data analysis: an expanded sourcebook. 2nd edn. London: Sage Publications, 1994: 50-74.

20. Pope C, Ziebland S, Mays N. Qualitative research in health care. Analysing qualitative data. BMJ 2000; 320(7227): 114-116.

21. Tolhurst H, Talbot J, Baker L, et al. Rural general practitioner apprehension about work related violence in Australia. Aust J Rural Health 2003; 11(5): 237-241.

22. Koritsas S, Coles J, Boyle M, Stanley J. Prevalence and predictors of occupational violence and aggression towards GPs: a cross-sectional study. Br J Gen Pract 2007; 57(545): 967-970.

23. Rippon TJ. Aggression and violence in health care professionals. J Adv Nurs 2000; 31(2): 452-460. 